\title{
CARACTERIZAÇÃO DE ARGAMASSAS PARA USO EM SISTEMAS DE VEDAÇÃO VERTICAL EXTERNO (SVVE)
}

\author{
Vagner Arruda de Castro \\ Núcleo de Pesquisa em Construção Civil, Petróleo e Desenvolvimento Sustentável IFRN, \\ Natal-Central, Bolsista PIBITI-CNPQ.vagner_arruda@yahoo.com.br \\ Marcos Alyssandro Soares dos Anjos
}

Núcleo de Pesquisa em Construção Civil, Petróleo e Desenvolvimento Sustentável, IFRN, Natal-Central, Professor Doutor do Instituto Federal de Educação, Ciência e Tecnologia do Rio Grande do Norte. marcos.anjos@ifrn.edu.br

\section{Edilberto Vitorino de Borja}

Núcleo de Pesquisa em Qualidade e Produtividade no Setor da Construção Civil, IFRN, Natal-Central, Professor Mestre do Instituto Federal de Educação, Ciência e Tecnologia do Rio Grande do Norte. edilberto.borja@ifrn.edu.br

Renato Samuel Barbosa de Araújo

Núcleo de Pesquisa em Tecnologia da Gestão da Indústria e Serviços, IFRN, Natal-Central, Professor Doutor do Instituto Federal de Educação, Ciência e Tecnologia do Rio Grande do

Norte. Renato.araujo@ifrn.edu.br

\section{RESUMO}

A Associação Brasileira de Normas Técnicas publicou em maio de 2010 uma nova norma de desempenho, a NBR 15.575, referente as edificações de até cinco pavimentos. Essa norma trará impactos importantes a fabricantes de materiais, projetistas, construtoras e prestadores de serviços, portanto os laboratórios de construção civil, como o LCC do IFRN, devem estar atentos a implicações destas normas, buscando gerar conhecimento a cerca dos aspectos nela envolvida, quanto para estarem aptos a avaliarem os materiais de construção e os sistemas construtivos empregados nas edificações abordadas na norma. Dentro deste contexto este artigo pretende caracterizar argamassas de revestimento para uso em sistema de vedação vertical externo (SVVE) compostos de blocos cerâmicos, revestidos com argamassas em diferentes composições, visando propor inovações tecnológicas aplicados ao processo de produção de SVVE, objetivando a melhoria de desempenho, qualidade e custo dos SVVE.

PALAVRAS-CHAVE: argamassa de revestimento, sistemas de vedação vertical externo, propriedades no estado fresco.

\section{CHARACTERIZATION OF MORTAR FOR USE IN EXTERNAL VERTICAL SEALING SYSTEMS (SVVE)}

\begin{abstract}
From May 2010 until the building of five floors have to be subjected to a new standard of performance, the NBR 15575 (ABNT, 2010). This standard will bring major impacts to materials manufacturers, designers, builders and contractors, so the construction of laboratories, as the LCC IFRN, should be aware of implications of these rules, seeking to generate knowledge about the aspects involved in it, as to be able to evaluate building materials and construction systems used in buildings covered in the standard. Within this
\end{abstract}


CASTRO, et al (2010)

context this project aims to assess external vertical sealing system
(VESE) consisting of ceramic bricks, mortar coated with different compositions, to propose technological innovations applied to the production process VESE and designed to improve performance, quality and cost of VESE.

KEY-WORD: mortar coating, vertical external wall systems, fresh properties. 


\section{CARACTERIZAÇÃO DE ARGAMASSAS PARA USO EM SISTEMAS DE VEDAÇÃO VERTICAL EXTERNO (SVVE)}

\section{INTRODUÇÃO}

Sistemas de vedação vertical interno e externo (SVVIE) são partes do edifício que limitam verticalmente o edifício e seus ambientes internos, controlando o fluxo de agentes solicitantes. A edificação habitacional deve reunir características que atendam às exigências de desempenho térmico, considerando-se a região de implantação da obra e as respectivas características bioclimáticas definidas na ABNT NBR 15220-3 e considerando-se que o desempenho térmico do edifício depende do comportamento interativo entre fachada, cobertura e piso.

A adição de fibra em materiais cimentícios tem a finalidade de aumentar a resistência à tração, diminuir a retração plástica e aumentar a tenacidade à fratura. Os principais fatores que controlam o desempenho dos compósitos cimentícios reforçados por fibras são as propriedades físicas e mecânicas das matrizes e das fibras, além da ligação entre os dois materiais, ou seja, a interface fibra-matriz (Hannant, 1978).

Um fator crítico para as argamassas reforçadas por fibras é a trabalhabilidade, pois com o aumento nos teores de fibras os compósitos perdem esta propriedade tornando difícil sua aplicação, assim as fibras são usadas em percentual relativamente baixo devido principalmente a dificuldade de mistura pelos métodos convencionais. Para SILVA \& BARROS (2007) um fator preponderante em argamassas com fibras é o efeito da condição de mistura das fibras, se estas são adicionadas às misturas secas ou molhadas, além do tipo de misturador.

Um dos maiores problemas das argamassas de revestimento é a aderência ao substrato e a baixa resistência à tração, além da alta retração das argamassas comuns. A adição de fibra em materiais cimentícios tem a finalidade de aumentar a resistência à tração, diminuir a retração plástica e aumentar a tenacidade à fratura, o que justifica a análise de dosagens e procedimentos que levam a adição de fibras em argamassas.

As argamassas de revestimento tem diversas funções numa habitação como a de regularização e proteção do elemento de vedação, proteção térmica e acústica, estanqueidade, seguranças estrutural e estética, para tanto ela deve atender à requisitos específicos que dependem do tipo de revestimento decorativo que irá receber, das condições de produção e aplicação, além do micro-clima e região onde esta argamassa será aplicada, para garantir assim a durabilidade do sistema de revestimento.

No Brasil a maior parte das argamassas de assentamento e revestimento são argamassas comuns produzidas em obra, normalmente sem uma dosagem adequada e nem um controle rígido de qualidade, o que vem acarretando diversas patologias nas argamassas como desplacamento dos revestimentos, esfarelamento e eflorescências. A NBR 15575 preconiza que a vida útil de projeto dos sistemas de vedação externa (paredes de vedação externa, painéis de fachada e fachadas cortina) seja entre o intervalo de 40 a 60 anos.

As inúmeras patologias nos revestimentos externos das edificações decorrem, principalmente, das falhas de projeto e de execução. Como as construções estão, atualmente, cada vez mais altas e flexíveis, é indispensável que as práticas executivas adotadas até então se adaptem aos novos processos construtivos (Gomes, Neves, \& Souza, 2007). Um dos maiores problemas 
das argamassas de revestimento é a aderência ao substrato e a baixa resistência à tração, além da alta retração das argamassas comuns.

\section{FUNDAMENTAÇÃO TEÓRICA}

Os sistemas de argamassas para revestimento estão sujeitos a diversas ações como as cargas mecânicas como cargas estáticas e dinâmicas, os efeitos das intempéries, além da poluição do meio ambiente (Guimarães, 2002).

A aderência das argamassas ao substrato depende das propriedades da argamassa no estado fresco como: teor de ar incorporado, massa específica, retenção de água, aderência inicial, retração por secagem; dos procedimentos de execução do revestimento; da natureza e características do substrato; das condições de temperatura e umidade no local de aplicação.

A capacidade de aderência das argamassas aos substratos é dividida em duas etapas, a primeira é a capacidade de aderência inicial, no estado fresco, que está relacionada com a entrada da pasta nos poros, reentrâncias e saliências do substrato, seguido do endurecimento progressivo da pasta (Maciel, Barros, \& Sabbatini, 1998). A segunda é a aderência mecânica, no estado endurecido, que é a propriedade da argamassa manter-se fixa ao substrato suportando as tensões normais e tangenciais que se desenvolvem na interface argamassasubstrato. Esta propriedade está relacionada com a dosagem da argamassa como teor e natureza dos aglomerantes, granulometria e teor de finos da argamassa e das características do substrato, como tipo e porosidade.

A adição de fibra em materiais cimentícios tem a finalidade de aumentar a resistência à tração, diminuir a retração plástica e aumentar a tenacidade à fratura, o que justifica a análise de dosagens e procedimentos que levem a adição de fibras em sistemas de argamassas utilizados na Construção Civil.

Vários fatores estão envolvidos na interação fibra-matriz entre eles estão a geometria da fibra (fator de forma); a condição da matriz, se esta apresenta-se fissurada ou não, o que interfere no mecanismo de transferência de tensões; o tipo de fibra; as características superficiais da fibra; a rigidez axial da fibra; o tipo de material da matriz; a orientação das fibras (fibras alinhadas ou aleatoriamente distribuídas); a velocidade de carregamento; e a durabilidade das fibras no compósito (Bentur \& Mindess, 1990).

Esta pesquisa tem como objetivo investigar a influência da adição de fibra de sisal curta e da fibra de polipropileno nas propriedades no estado fresco e endurecido das argamassas de revestimento.

De forma específica, o objetivo deste trabalho é realizar ensaios com vistas a definir algumas características básicas tais como: consistência, teor de ar incorporado, densidade de massa, índices físicos, resistência à compressão, resistência à tração por compressão diametral, resistência à aderência e módulo de deformação longitudinal.

\section{METODOLOGIA}

Este trabalho procura verificar a influência da adição de cal, fibra de sisal e polipropileno nas propriedades de argamassas de revestimento no estado fresco e endurecido, para tanto foram utilizados dois traços como referência, 1:4 e 1:1:6 (traços em volume), traços estes bastante utilizados na região nordeste do Brasil, seja para argamassa de assentamento ou revestimento. 
A partir dos traços de referência serão adicionadas fibras de sisal e polipropileno em frações volumétricas $\left(V_{f}\right)$ de $0,15 \%$ e $0,6 \%$, ou seja, porcentagem de fibras em relação ao volume de argamassa.

\section{MATERIAIS}

Para a produção das argamassas foram utilizados os materiais listados abaixo, cujas propriedades estão assinaladas na tabela 1, e a granulometria da areia é apresentada na figura 1.

- $\quad$ Cimento: Portland CP II Z 32.

- $\quad$ Agregado miúdo: Areia fina.

- $\quad$ Cal: Carbomil

- $\quad$ Fibras de polipropileno com $10 \mathrm{~mm}$ de comprimento.

- $\quad$ Fibras de Sisal com comprimento aproximado de $10 \mathrm{~mm}$ obtidas com produtores do estado da Paraíba.

- Aditivos Químicos:

\section{METODOS}

\section{Caracterização dos Materiais}

A caracterização dos materiais antecede todo trabalho de preparo das argamassas, sendo de fundamental importância para a correta utilização das mesmas. Os métodos de ensaios adotados para a caracterização dos materiais constam na tabela 1 .

Tabela 1. Métodos de ensaios para a caracterização dos materiais

\begin{tabular}{c|c}
\hline Determinação & Norma \\
\hline $\begin{array}{c}\text { Determinação da massa específica do agregado miúdo por } \\
\text { meio do frasco Chapman }\end{array}$ & (NBR 97761987) \\
\hline Determinação da massa unitária do agregado miúdo & $($ NBR 7251/1987) \\
\hline Determinação da composição granulométrica dos agregados & $($ NBR 7217/1987) \\
\hline Determinação do teor de materiais pulverulentos nos \\
agregados & $($ NBR 7218/1987) \\
\hline Massa Especifica do Cimento por meio do Frasco de Lê & $($ NBR - 6474/84) \\
\hline Determinação da Finura do Cimento & (NBR 5732) \\
\hline Tempo de Pega do Cimento & (NBR NM 65) \\
\hline Determinação da massa específica da pozolana & (NBR 6474) \\
\hline Determinação da finura da pozolana & (NBR 9202) \\
\hline
\end{tabular}




\section{ESTUDO DA DOSAGEM DE ARGAMASSA DE REVESTIMENTO}

Serão utilizados seis traços de argamassas de revestimento a serem utilizadas nos SVVE, dois de uso consagrado na construção civil:
A. Traço $1-1: 4$ (cimento:areia);
B. Traço $2-1: 1: 6$ (cimento:cal:areia);
C. E quatro traços propostos a partir de estudos de dosagens para inclusão das fibras de sisal e fibras de polipropileno.
D. traços com cinza de biomassa da cana-de-açúcar

\section{ESTUDO DA DOSAGEM DE ARGAMASSA DE REVESTIMENTO}

Os traços serão misturados por 5 minutos em argamassadeira tipo planetária, com capacidade de 5 litros. Logo após a mistura será retirada uma amostra da argamassa para determinação das propriedades no estado fresco, conforme tabela 2, em seguida as argamassas serão lançadas nos painéis de blocos cerâmicos $(1,20 \mathrm{~m}$ x $1,20 \mathrm{~m}$ x $0,20 \mathrm{~m})$ devidamente chapiscada.

Tabela 2. Métodos de ensaios para determinação das propriedades das argamassas no estado fresco

\begin{tabular}{c|c}
\hline Determinação & Norma \\
\hline Índice de consistência & NBR 13276/2005 \\
\hline Densidade de massa e teor de ar incorporado & NBR 13278/2005 \\
\hline
\end{tabular}

Tabela 3. Métodos de ensaios para determinação das propriedades das argamassas no estado endurecido

\begin{tabular}{c|c}
\hline Determinação & Norma \\
\hline Resistência à tração na flexão e à compressão & NBR 13279 \\
\hline Resistência à tração por aderência & NBR 15258 \\
\hline Permeabilidade por capilaridade & NBR 9779 \\
\hline Resistência a tração diametral & NBR 13278 \\
\hline Densidade de massa e teor de ar incorporado &
\end{tabular}

\section{PRODUÇÃO DOS PAINÉIS SVVE}

Os corpos-de-prova serão painéis de SVVE produzidos de acordo com a NBR 15575-4 (ABNT, 2010). Serão produzidos 10 painéis de SVVE, onde cinco serão submetidos à ação de calor e resfriamento proposto na NBR 15575-4 e cinco serão utilizados como referência sem a exposição. 


\section{AVALIAÇÃO DOS PAINÉIS SVVE}

Serão realizados ensaios de resistência de aderência à tração das argamassas de revestimento dos 10 painéis de SVVE, além da avaliação da ocorrência de degradação, e comportamento térmico dos painéis.

\section{ANÁLISE E INTERPRETAÇÃO DOS DADOS}

Até o presente momento foram produzidas argamassas de referência contendo as dosagens 1:4 e 1:1:6 (traço por unidade de volume) cuja a caracterização dos materiais utilizados para a produção das mesmas estão listadas na tabela 3 e a granulometria da areia apresentada na figura 1 abaixo. Foram ainda determinadas as propriedades dessas argamassas no estado fresco conforme a tabela 4 .

Tabela 3 - Caracterização dos materiais

\begin{tabular}{c|c|c|c}
\hline & Areia & Cimento & Cal \\
\hline Massa unitária & $1,55 \mathrm{~g} / \mathrm{cm}^{3}$ & $1,25 \mathrm{~g} / \mathrm{cm}^{3}$ & $0,42 \mathrm{~g} / \mathrm{cm}^{3}$ \\
\hline Massa específica & $2,61 \mathrm{~g} / \mathrm{cm}^{3}$ & $3,0 \mathrm{~g} / \mathrm{cm}^{3}$ & $2,02 \mathrm{~g} / \mathrm{cm}^{3}$ \\
\hline Diâmetro máximo & $2,4 \mathrm{~mm}$ & - & - \\
\hline Módulo de finura & & - & - \\
\hline
\end{tabular}

Tabela 4 - Determinação das propriedades das argamassas no estado fresco

\begin{tabular}{l|c|c}
\hline \multirow{2}{*}{ Determinação } & \multicolumn{2}{c}{ Traço } \\
\cline { 2 - 3 } & $1: 4$ & $1: 1: 6$ \\
\hline Índice de Consistência & $25,75 \mathrm{~cm}$ & $25,00 \mathrm{~cm}$ \\
\hline Fator Água/ Cimento & 0,60 & 0,71 \\
\hline Teor de Ar Incorporado (NBR NM47-Aparelho) & $7,5 \%$ & $5 \%$ \\
\hline Teor de Ar Incorporado (NBR 13278) & $6,6 \%$ & $5,5 \%$ \\
\hline Densidade de Massa & $2,08 \mathrm{~g} / \mathrm{cm}^{3}$ & $2,06 \mathrm{~g} / \mathrm{cm}^{3}$ \\
\hline
\end{tabular}




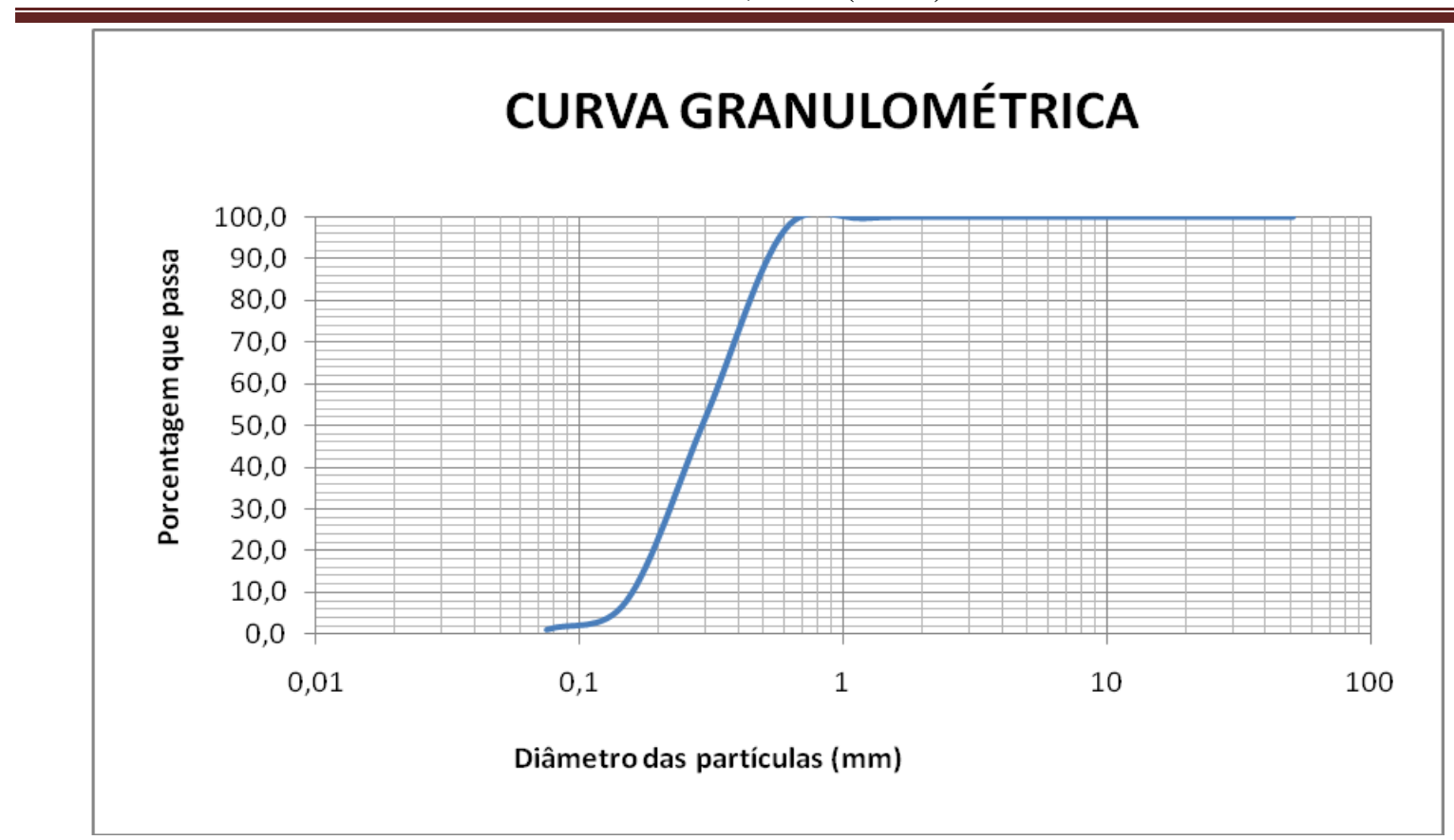

Figura 1. Granulometria da areia

Foi verificado que o traço 1:1:6 apresentou um índice de consistência menor que o traço 1:4, devido a adição da cal, pois a mesma apresenta uma finura próxima ao cimento aumentado assim a superfície específica dos aglomerantes usados neste traço, requerendo, portanto, uma quantidade maior de água, o que justifica a aumento do fator água/cimento.

Os resultados dos teores de ar incorporado determinados segundo a NBR 13278 e a medida por aparelho medidor de ar incorporado, se mostram um pouco diferentes para os traços analisados, no entanto esta diferença foi pequena, $0,9 \%$ e $0,5 \%$ para os traços 1:4 e 1:1:6, respectivamente. Entretanto para efeitos de classificação da argamassa, segundo a NBR 13281 a diferença nas medições não altera a classificação, quanto ao ar incorporado, assim as argamassas analisada se enquadram no tipo B.

Percebeu-se que o aumento de ar incorporado na argamassa favoreceu sua trabalhabilidade quando no estado fresco. Na argamassa dosada com o traço 1:1:6, a cal favoreceu maior trabalhabilidade quando comparada ao traço 1:4, promovendo uma melhor plasticidade, consistência e retenção de água.

\section{CONSIDERAÇÕES FINAIS}

O presente trabalho estar sendo desenvolvido através de experimentos e ensaios realizados em laboratório e investigará o potencial de uso da fibra de sisal e polipropileno e de cinza de biomassa da cana-de-açúcar nas propriedades de argamassas de revestimento no estado fresco e endurecido submetido a ações de calor e choque térmico, visando avaliar as possibilidades de seu aproveitamento na construção civil. Dentro do escopo deste trabalho, as seguintes conclusões que até o presente momento puderam ser extraídas a partir dos resultados obtidos foram:

- O traço 1:1:6 apresentou um índice de consistência menor que o traço 1:4, devido a adição da cal; 
- O aumento de ar incorporado na argamassa favoreceu sua trabalhabilidade quando no estado fresco;

- No traço 1:1:6, a cal favoreceu maior trabalhabilidade quando comparada ao traço 1:4, promovendo uma melhor plasticidade e consistência.

O presente trabalho encontra-se em seu estágio inicial de pesquisa, espera-se que mais resultados sejam divulgados em breve com o intuito de contribuir positivamente para comunidade científica e setor da construção civil.

\section{REFERÊNCIAS}

1. ANJOS, M. A. S., W. Silva, H. Alves, e P. Souza Junior. Avaliação das propriedades de sistemas de revestimento de argamassas reforçadas por fibras naturais e sintéticas. III CONNEPI. Fortaleza, 2008. 1-9.

2. GOMES, A. O., C. NEVES, e S. L. M. SOUZA. Utilização de telas em sistemas de revestimentos com argamassa. VII simpósio brasileiro de tecnologia das argamassas. Recife: ANTAC, 2007. 1-8.

3. GUIMARÃES, J. E. P. A cal: Fundamentos e aplicações na engenharia civil. $2^{\circ}$ Edição. São Paulo: Pini, 2002.

4. MACIEL, L. L., M. M. BARROS, e F. H. SABBATINI. Recomendações para Execução de Revestimentos de Argamassas Para Paredes de Vedação Internas, Exteriores e Teto. São Paulo: EPUSP, 1998. 